\title{
STRUCTURALLY DYNAMIC MODELS OF LAKES
}

\author{
SVEN ERIK JØRGENSEN \\ Copenhagen University, Institute A, Section of Environmental Chemistry, University Park, Copenhagen.
}

\begin{abstract}
Lakes as all other ecosystems are adaptive, have self-organization, and change the species compositions in accordance with the variable forcing functions. Therefore, models that can capture this dynamics are needed, which means that the properties (represented in models by the parameter) of the biological components of the model are continuously changed. This paper presents what is denoted as structural dynamic models (SDMs) that can capture this dynamics of changing the ecosystem structure. A SDM uses a goal function to determine the changes of the parameters. Eco-exergy is used as goal function, which is the work capacity (work energy) of the ecosystem. The use of this goal function can be considered a translation of Darwin's theory to thermodynamics. In 23 case studies, it has been possible to use SDM to describe the structural changes with an acceptable standard deviation. Of these cases, 12 were lake models and an attempt is made in this paper to summarize the experience gained by the use of SDMs on lakes. The three most characteristic case studies are presented in more detail and conclusions on the applicability of SDM on lakes are summarized.
\end{abstract}

Keywords: Adaptation, eco-exergy, lake models, shift in species composition, structural dynamics.

\section{INTRODUCTION}

Ecological models attempt to capture the characteristics of ecosystems. However, ecosystems differ from most other systems by being extremely adaptive, having the ability of self-organization, and having a large number of feedback mechanisms. Even a shift in species composition can take place. The real challenge of modeling is therefore: How can we construct models that are able to reflect these very dynamic characteristics? Some recent development has attempted to answer this question by the application of what is denoted as structural dynamic models (SDMs) or variable parameter models - sometimes also named the fifth generation of models. The thermodynamic variable eco-exergy (it is free energy or work capacity defined for ecosystems; the definition and presentation is given below) has been applied to develop SDMs in 23 cases; see Zhang et al. [1], Jørgensen [2], Jørgensen [3] and Jørgensen and Fath [37]. Of these models, 12 have been lake models:

1. (1-8) Eight eutrophication models of six different lakes,

2. (9) a model to explain the success and failure of biomanipulation based on removal of planktivorous fish,

3. (10) a model to explain under what circumstances submerged vegetation and phytoplankton are dominant in shallow lakes,

4. (11) a model of Lake Balaton, which was used to support the intermediate disturbance hypothesis, and

5. (12) the SDM included in PAMOLARE 1 developed by UNEP has been applied on Lake Fure in Denmark.

The paper will summarize the experience gained by the use of SDMs on lakes and present a few characteristic illustrative examples to demonstrate the benefits that SDMs can offer the ecological modeler of lakes: better prognoses and improved calibration. Before presenting these benefits, however, it is necessary to show how to construct a SDM and define eco-exergy that is used as goal function in this model type.

(C) 2012 WIT Press, www.witpress.com

ISSN: 1755-7437 (paper format), ISSN: 1755-7445 (online), http://journals.witpress.com

DOI: $10.2495 / \mathrm{DNE}-\mathrm{V} 7-\mathrm{N} 2-117-139$ 


\section{HOW TO CONSTRUCT SDMS AND DEFINITIONS OF ECO-EXERGY?}

Species are continuously tested against the prevailing conditions (external as well as internal factors) and the best fitted are selected and are able to maintain and even increase their biomass; see Fig. 1. The property of fitness must, of course, be heritable to have any effect on the species composition and the ecological structure of the ecosystem in the long run. How can we account for these features in modeling?

If we follow the generally applied modeling procedure presented in most textbooks on ecological modeling, see Jørgensen, [3], we will develop a model that describes the processes in the focal ecosystem, but the parameters will represent the properties of the state variables as they are in the ecosystem during the examination period. They are not necessarily valid for another period because we know that an ecosystem can regulate, modify, and change them, if needed as response to changes in the existing conditions (see Fig. 1), determined by the forcing functions and the interrelations between the state variables. Our present models have rigid structures and a fixed set of parameters meaning that no changes or replacements of the components are possible. We need to introduce parameters (properties) that can change according to changing forcing functions and general conditions for the state variables (components) to optimize continuously the ability of the system to move away from thermodynamic equilibrium. The idea is to test if a change of the most crucial parameters produces a higher well-selected and defined goal function of the system and, if that is the case, to use that set of parameters.

The model type that can account for the change in species composition as well as for the ability of the species to adapt, that is, the biological components of our models, to change their properties, that is, to adapt to the existing conditions imposed on the species, is as mentioned above called

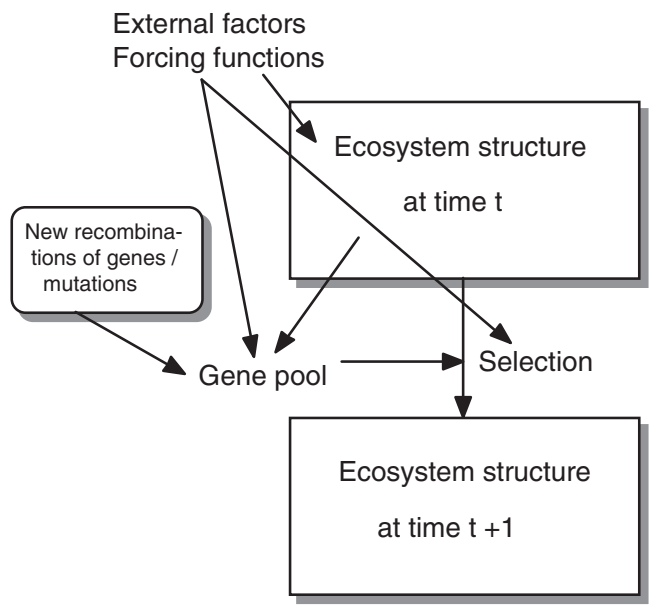

Figure 1: Conceptualization of how the external factors steadily change the species composition. The possible shifts in species composition are determined by the gene pool, which is steadily changed due to mutations and new sexual recombinations of genes. The development is, however, more complex. This is indicated by arrows from 'structure' to 'external factors' and 'selection' to account for the possibility that the species can modify their own environment (see below) and thereby their own selection pressure; (2) an arrow from 'structure' to 'gene pool' to account for the possibilities that the species can to a certain extent change their own gene pool. 
SDM, to indicate that they are able to capture structural changes. They may be called the next or fifth generation of ecological models to underline that they are radically different from previous modeling approaches and can do more, namely describe the adaptation and changes in species composition.

It could be argued that the ability of ecosystems to replace the present species with other better-fitted species can be considered by constructing models that encompass all actual species for the entire period that the model attempts to cover. This approach has, however, two essential disadvantages. First, the model becomes very complex, as it will contain many state variables for each trophic level. Therefore, the model will contain many more parameters that have to be calibrated, and this will introduce a high uncertainty to the model and will render the application of the model very case-specific $[4,5]$. In addition, the model will still be rigid and not allow for continuously changing parameters due to adaptation.

Straskraba [6] and [7] uses a maximization of biomass as the governing principle. The model computes the biomass and adjusts one or more selected parameters to achieve the maximum biomass at every instance. The model has a routine that computes the biomass for all possible combinations of parameters within a given realistic range. The combination that gives the maximum biomass is selected for the next time step and so on. Biomass can only be used when only one state variable is adapting or shifted to other species.

Exergy (work capacity or free energy for a far from thermodynamic equilibrium system) calculated for ecosystems by the use of a special reference system, eco-exergy - has been widely used as a goal function in ecological models, and some of the most illustrative case studies of lake models are presented and discussed below. Eco-exergy has two pronounced advantages as goal function for development of SDMs. It is defined as far from thermodynamic equilibrium and it is related to the state variables, which are easily determined or measured, opposite, for instance, maximum power that is related to the flows. Furthermore, eco-exergy can be applied also when two or more species are adapting and shifted to other species, which is often the case. Phytoplankton and zooplankton are, for instance, often changed simultaneously, when the forcing function of lakes are changed. As eco-exergy is not a generally used thermodynamic function, we need, however, first to present this concept. Eco-exergy expresses energy with a built-in measure of quality like emergy. It is defined as the ecosystem content of free energy that can work (see also Fig. 2) with the same system at thermodynamic equilibrium as reference state.

Let us try to translate Darwin's theory into thermodynamics, applying eco-exergy as the basic concept. Survival implies biomass maintenance, and growth means biomass increase. It costs free energy that can work to construct biomass and biomass, therefore, possesses eco-exergy, which is transferable to support other exergetic (energetic) processes. Survival and growth can, therefore, be measured by use of the thermodynamic concept eco-exergy, which may be understood as the free energy relative to a reference state for a far from thermodynamic equilibrium system. Darwin's theory can, therefore, be reformulated in thermodynamic terms as follows: The prevailing conditions of an ecosystem steadily change and the system will continuously select the species, and thereby the processes that can contribute most to the maintenance or even growth of the ecoexergy of the system means it move further away from thermodynamic equilibrium.

Jørgensen and Mejer [8] have shown by the use of thermodynamics that the following equation is valid for the components of an ecosystem:

$$
\begin{gathered}
\mathbf{i}=\mathbf{n} \\
\text { Eco-ex }=\operatorname{RT~} \Sigma\left(\mathrm{C}_{\mathrm{i}} * \ln \left(\mathrm{C}_{\mathrm{i}} / \mathrm{C}_{\mathrm{eq}, \mathrm{i}}\right)-\left(\mathrm{C}_{\mathrm{i}}-\mathrm{C}_{\mathrm{eq}, \mathrm{i}}\right)\right), \\
\mathbf{i}=\mathbf{1}
\end{gathered}
$$

where $\mathrm{R}$ is the gas constant, $\mathrm{T}$ the temperature of the environment (Kelvin), while $\mathrm{C}_{\mathrm{i}}$ represents the ith component expressed in a suitable unit, for example, for phytoplankton in a lake $C_{i}$ could be 


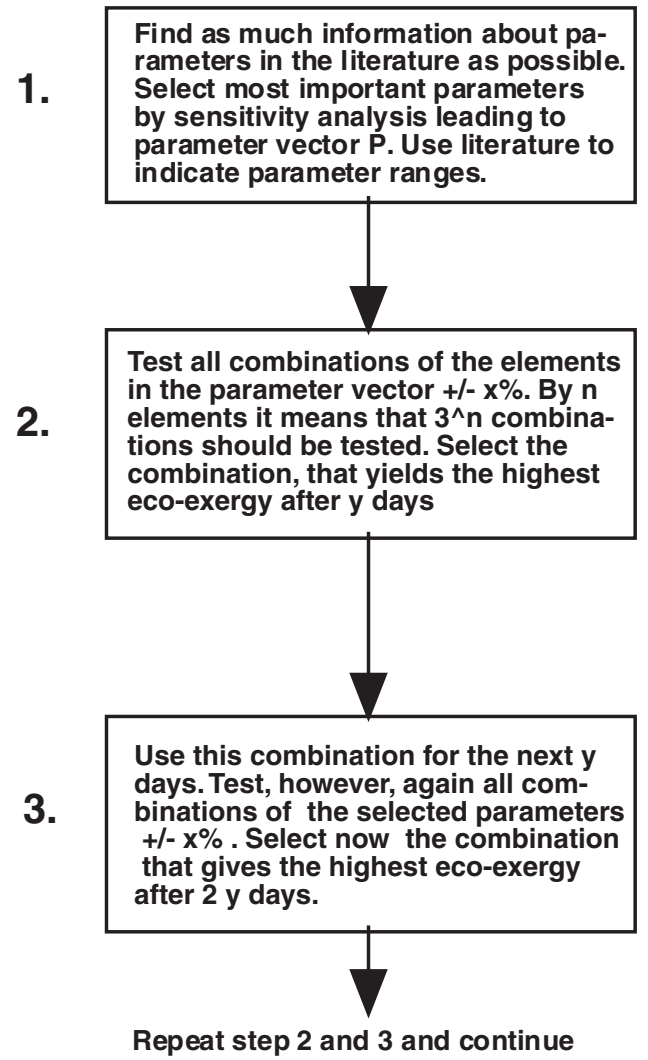

Figure 2: The procedure used for the development of SDMs.

milligrams of a focal nutrient in the phytoplankton per liter of lake water, $\mathrm{C}_{\mathrm{eq}, \mathrm{i}}$ is the concentration of the ith component at thermodynamic equilibrium.

The idea of SDMs is to continuously find a new set of parameters (limited for practical reasons to the most crucial, i.e. sensitive parameters) that is better fitted for the prevailing conditions of the ecosystem. 'Fitted' is defined in the Darwinian sense by the ability of the species to survive and grow, which may be measured by the use of eco-exergy [9-15], and [8]. Figure 3 shows the proposed modeling procedure, which has been applied in the two cases presented below.

Eco-exergy is defined as the work the system can perform when it is brought into equilibrium with the environment or another well-defined reference state. If we presume a reference environment for a system at thermodynamic equilibrium, meaning that all the components are: (1) inorganic, (2) at the highest possible oxidation state signifying that all free energy has been utilized to do work, and (3) homogeneously distributed in the system, meaning no gradients, then the situation illustrated in Fig. 2 is valid. It is possible to distinguish between bio-chemical exergy and chemical-physical exergy. The chemical energy embodied in organic compounds and biological structure contributes most to the exergy content of ecological systems. Exergy was introduced in the 1950s to account for the energy that can do work in technological context. The reference state was the environment of the consider system. For ecosystems, the environment is the next ecosystem, and it would be irrelevant to use as reference state. Therefore, the same system but at thermodynamic equilibrium has been chosen as reference state. 


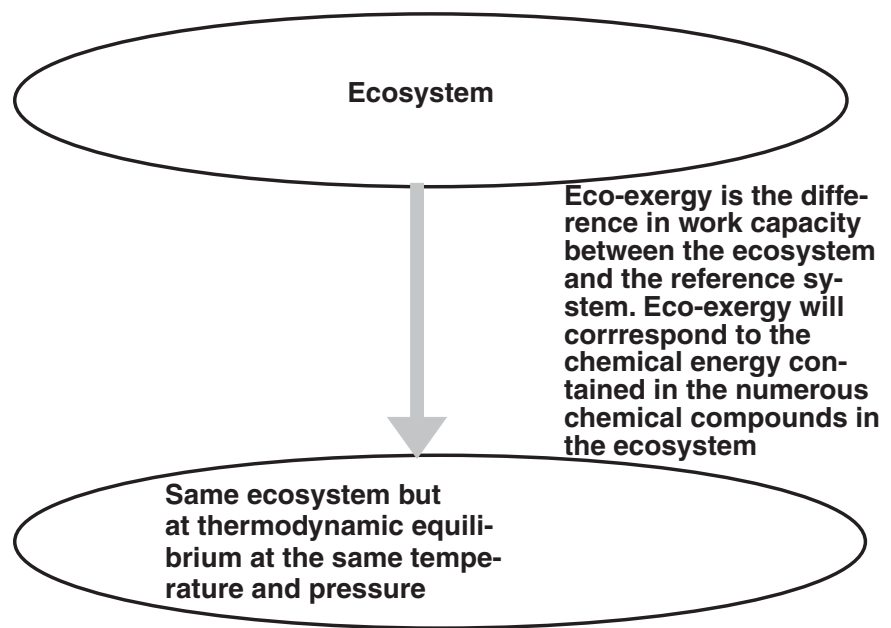

Figure 3: The definition of eco-exergy is shown. The work capacity in the ecosystem in the form of chemical energy of many different and complex chemical compounds relative to the reference system is the eco-exergy. The reference system is the same ecosystem but at thermodynamic equilibrium, that is, a homogeneous system without life. All the chemical compounds are inorganic and there are no gradients.

Temperature and pressure differences between systems and their reference environments are small in contribution to overall eco-exergy and for the present purposes can be ignored. We will compute the eco-exergy based entirely on bio-chemical energy: $\sum \mathrm{i}(\mu \mathrm{c}-\mu \mathrm{c}, \mathrm{o}) \mathrm{Ni}$, where $\mathrm{i}$ is the number of exergy-contributing compounds, $\mathrm{c}$, and $\mu \mathrm{c}$ are the chemical potential relative to that at a reference inorganic state, $\mu c, o$. Our (chemical) exergy index for a system will be taken with reference to the same system at the same temperature and pressure, but in the form of a pre-biotic environment without life, biological structure, information, or organic molecules - it means an inorganic soup.

By using this particular exergy, denoted eco-exergy, based on the same system at thermodynamic equilibrium as reference and at the same temperature and pressure, the eco-exergy becomes dependent only on the chemical potential of the numerous biochemical components, controling the life processes.

In accordance with Jørgensen and Svirezhev [16], it is possible to show that eco-exergy density for a model can be found as

$$
\begin{gathered}
\mathrm{i}=\mathrm{n} \\
\text { Eco-exergy density }=\Sigma \beta_{\mathrm{i}} \mathrm{c}_{\mathrm{i}} \mathrm{i}=1
\end{gathered}
$$

The eco-exergy due to the 'fuel' value of organic matter (chemical energy) is about $18.7 \mathrm{~kJ} / \mathrm{g}$ (compare with coal: about $30 \mathrm{~kJ} / \mathrm{g}$ and crude oil: $42 \mathrm{~kJ} / \mathrm{g}$ ). It can be transferred to other energy forms, for instance, mechanical work directly and be measured by bomb calorimetry, which requires destruction of the sample (organism), however. The information eco-exergy $=(\beta-1) *$ biomass or density of information eco-exergy $=(\beta-1) *$ concentration. The information eco-exergy controls the function of the many biochemical processes. The ability of a living system to do work is contingent upon its function as a living dissipative system. Without the information eco-exergy, the organic matter could only be used as fuel similar to fossil fuel. But due to the information eco-exergy, 
organisms are able to make a network of the sophisticated biochemical processes that characterize life. The eco-exergy (of which the major part is embodied in the information) is a measure of the organization [16]. This is the intimate relationship between energy and organization that Schrødinger [17] was struggling to find. The $\beta$-values determine by various methods, mainly based on the genome, are listed in Table 1, in accordance with Jørgensen et al. [18].

The application of eco-exergy to develop SDMs is based on what may be considered thermodynamic translation of survival of the fittest, as already discussed above. Biological systems have many possibilities for moving away from thermodynamic equilibrium, and it is important to know along which pathways among the possible ones a system will develop.

In the following sections, SDMs of lakes will be presented as illustrative examples. Three examples of structural changes that SDMs have been able to capture are presented. In the example of development of a SDM to describe the competition between phytoplankton and submerged vegetation, it will be shown how the application of SDM improves the calibration.

\section{BIOMANIPULATION}

This example of the use of SDM to understand the observed reactions by the use of biomanipulation is presented in more details in Jørgensen and Fath (2011). The eutrophication and remediation of a lacustrine environment do not proceed according to a linear relationship between nutrient load and vegetative biomass but rather display a sigmoid trend with delay, as shown in Fig. 4. The hysteresis reaction is completely in accordance with observations $[19,20]$ and it can be explained by structural changes [19, 21-23]. A lake ecosystem shows a marked buffering capacity to increasing nutrient level, which can be explained by a current increasing removal rate of phytoplankton by grazing and settling. Zooplankton and fish abundance are maintained at relatively high levels under these circumstances. At a certain level of eutrophication, it is not possible for zooplankton to increase the grazing rate further, and the phytoplankton concentration will increase very rapidly by slightly increasing the concentrations of nutrients. When the nutrient input is decreased under these conditions, a similar buffering capacity to variation is observed. The structure has now changed to a high concentration of phytoplankton and planktivorous fish, which causes a resistance and delay to a change where the second and fourth trophic levels become dominant again.

Willemsen [24] distinguishes two possible conditions:

(1) A bream state characterized by turbid water, high eutrophication, low zooplankton concentration, absent of submerged vegetation, large amount of breams, while pike is hardly found.

(2) A pike state, characterized by clear water and low eutrophication. Pike and zooplankton are abundant and there are significant fewer breams.

The presence of two possible states in a certain range of nutrient concentrations may explain why biomanipulation has not always been used successfully. According to the observations referred to in the literature, success is associated with a total phosphorus concentration below $50 \mu \mathrm{g} / \mathrm{L}[25]$ or at least below 100-200 $\mu \mathrm{g} / \mathrm{L}$ [26], while disappointing results are often associated with phosphorus concentration above this level of more than approximately $120 \mu \mathrm{g} / \mathrm{L}$ [27] with a difficult control of the standing stocks of planktivorous fish [28, 29].

Scheffer [30] has used a mathematical model based on catastrophe theory to describe these shifts in structure. However, this model does not consider the shifts in species composition, which is of particular importance for biomanipulation. The zooplankton population undergoes a structural change when we increase the concentration of nutrients, for example, from a dominance of calanoid copepods to small caldocera and rotifers, according to the following references: de Bernardi and 
Table 1: ß-values = Exergy content relatively to the exergy of detritus [18].

\begin{tabular}{|c|c|c|c|}
\hline \multicolumn{2}{|c|}{ Early organisms Plants } & \multicolumn{2}{|r|}{ Animals } \\
\hline Detritus & & 1.00 & \\
\hline Virus & 1.01 & & \\
\hline Minimal cell & 5.8 & & \\
\hline Bacteria & & 8.5 & \\
\hline Archaea & & 13.8 & \\
\hline Protists & Algae & & 20 \\
\hline \multirow[t]{4}{*}{ Yeast } & & 17.8 & \\
\hline & & 33 & Mesozoa, Placozoa \\
\hline & & 39 & Protozoa, amoeba \\
\hline & & 43 & Phasmida (stick insects) \\
\hline \multirow[t]{4}{*}{ Fungi, moulds } & & 61 & \\
\hline & & 76 & Nemertina \\
\hline & & 91 & $\begin{array}{l}\text { Cnidaria (corals, sea anemones, } \\
\text { jelly fish) }\end{array}$ \\
\hline & Rhodophyta & 92 & \\
\hline \multirow[t]{21}{*}{ Porifera, sponges } & & 97 & Gatroticha \\
\hline & & 98 & \\
\hline & & 109 & Brachiopoda \\
\hline & & 120 & Platyhelminthes (flatworms) \\
\hline & & 133 & Nematoda (round worms) \\
\hline & & 133 & Annelida (leeches) \\
\hline & & 143 & Gnathostomulida \\
\hline & Mustard weed & 143 & \\
\hline & & 165 & Kinorhyncha \\
\hline & Seedless vas-cula plants & 158 & \\
\hline & & 163 & Rotifera (wheel animals) \\
\hline & & 164 & Entoprocta \\
\hline & Moss & 174 & \\
\hline & & 167 & $\begin{array}{l}\text { Insecta (beetles, fruit flies, bees, } \\
\text { wasps, bugs, ants) }\end{array}$ \\
\hline & & 191 & Coleodiea (Sea squirt) \\
\hline & & 221 & Lepidoptera (buffer flies) \\
\hline & & 232 & $\begin{array}{l}\text { Crustaceans, Mollusca, bivalvia, } \\
\text { gastropodea }\end{array}$ \\
\hline & & 246 & Chordata \\
\hline & Rice & 275 & \\
\hline & Gynosperms (incl. pinus) & 314 & \\
\hline & & 322 & Mosquito \\
\hline \multirow[t]{2}{*}{ Flowering plants } & & 393 & \\
\hline & & 499 & Fish \\
\hline
\end{tabular}


Table 1: Continued.

\begin{tabular}{lll}
\hline Early organisms Plants & \multicolumn{1}{c}{ Animals } \\
\hline & 688 & Amphibia \\
833 & Reptilia \\
980 & Aves (Birds) \\
2127 & Mammalia \\
2138 & Monkeys \\
2145 & Anthropoid apes \\
2173 & Homo sapiens \\
\hline
\end{tabular}

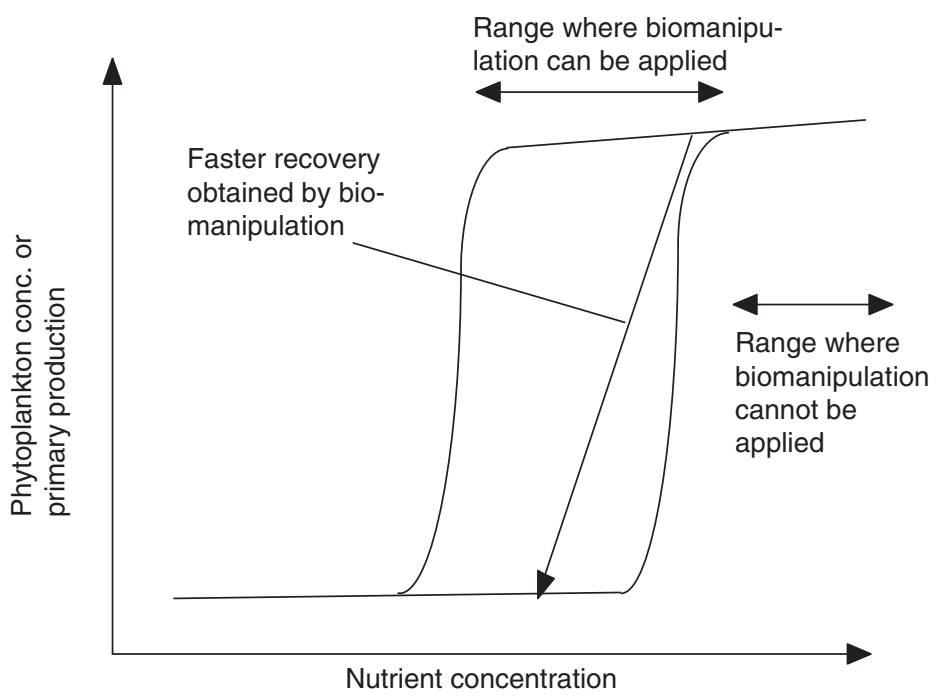

Figure 4: The hysteresis relation between nutrient level and eutrophication measured by the phytoplankton concentration is shown. The possible effect of biomanipulation is shown. An effect of biomanipulation can hardly be expected above a certain concentration of nutrients, as indicated in the diagram. The biomanipulation can only give the expected results in the range where two different structures are possible.

Giussani, [23] and Giussani and Galanti, [31]. Hence, a test of SDMs could be used to give a better understanding of the relationship between concentrations of nutrients and the vegetative biomass and to explain possible results of biomanipulation. This section refers to the results achieved by SDM with the aim to understand the above-described changes in structure and species compositions [32]. The applied model has six state variables: (1) dissolved inorganic phosphorus; (2) phytoplankton, phyt.; (3) zooplankton, zoopl.; (4) planktivorous fish, fish 1; (5) predatory fish, fish 2; and (6) detritus. The forcing functions are the input of phosphorus, in $\mathrm{P}$, and the through-flow of water determining the retention time. The latter forcing function determines also the outflow of detritus and phytoplankton. 
Simulations have been carried out for phosphorus concentrations in the in-flowing water of 0.02 , $0.04,0.08,0.12,0.16,0.20,0.30,0.40,0.60$, and $0.80 \mathrm{mg} / \mathrm{L}$. For each of these cases, the model was run for any combination of a phosphorus uptake rate of $0.06,0.05,0.04,0.03,0.02,0.011 / 24 \mathrm{~h}$ and a grazing rate of $0.125,0.15,0.2,0.3,0.4,0.5,0.6,0.8$ and $1.01 / 24 \mathrm{~h}$. When these two parameters were changed, simultaneous changes of phytoplankton and zooplankton mortalities were made according to allometric principles (see Peters [38]). The parameters, which are made variable to account for the dynamics in structure, are for phytoplankton growth rate (uptake rate of phosphorus) and mortality and for zooplankton growth rate and mortality.

The settling rate of phytoplankton was made proportional to the (length) ${ }^{2}$. Half of the additional sedimentation, when the size of phytoplankton increases corresponding to a decrease in the uptake rate, was allocated to detritus to account for resuspension or faster release from the sediment. A sensitivity analysis has revealed that exergy is most sensitive to the changes in these five selected parameters, which also represent the parameters which change significantly by size. The 6 respectively 9 levels selected above represent approximately the range in size for phytoplankton and zooplankton.

For each phosphorus concentration, 54 simulations were carried out to account for all combinations of the two key parameters. Simulations over 3 years, 1100 days, were applied to ensure that either steady state, limit cycles, or chaotic behavior would be attained. This SDM approach presumed that the combination with the highest exergy should be selected as representing the process rates in the ecosystem. If eco-exergy oscillates even during the last 200 days of the simulation, then the average value for the last 200 days was used to decide on which parameter combination it would give the highest eco-exergy. The combinations of the two parameters, the uptake rate of phosphorus for phytoplankton, and the grazing rate of zooplankton giving the highest exergy at different levels of phosphorus inputs are plotted in Figs. 5 and 6. The uptake rate of phosphorus for phytoplankton gradually decreases, when the phosphorus concentration increases. As seen, the zooplankton grazing rate changes at the phosphorus concentration 0.12 $\mathrm{mg} / \mathrm{L}$ from $0.41 / 24 \mathrm{~h}$ to $1.01 / 24 \mathrm{~h}$, that is, from larger species to smaller species, which is according to the expectations.

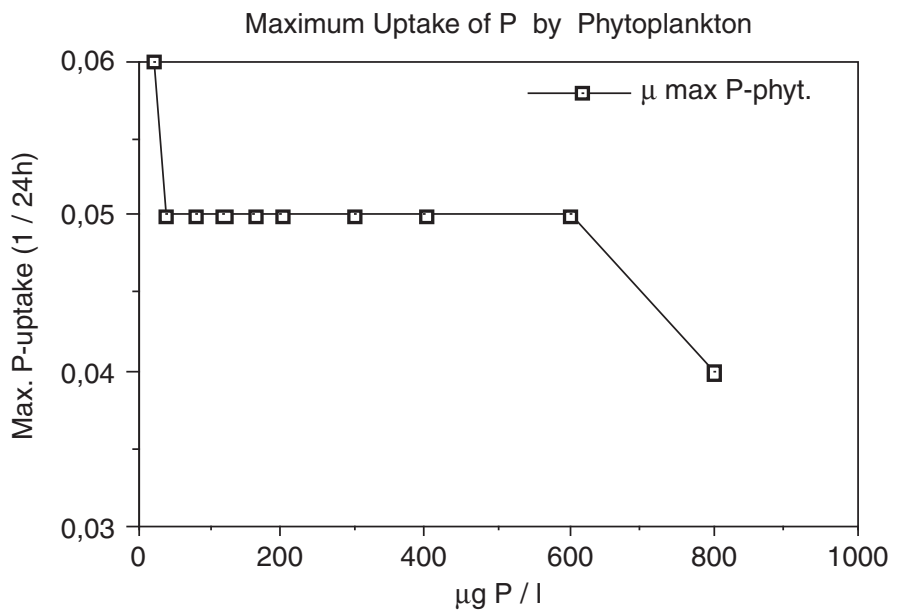

Figure 5: The maximum growth rate of phytoplankton obtained by the SDM approach is plotted against the phosphorus concentration. 


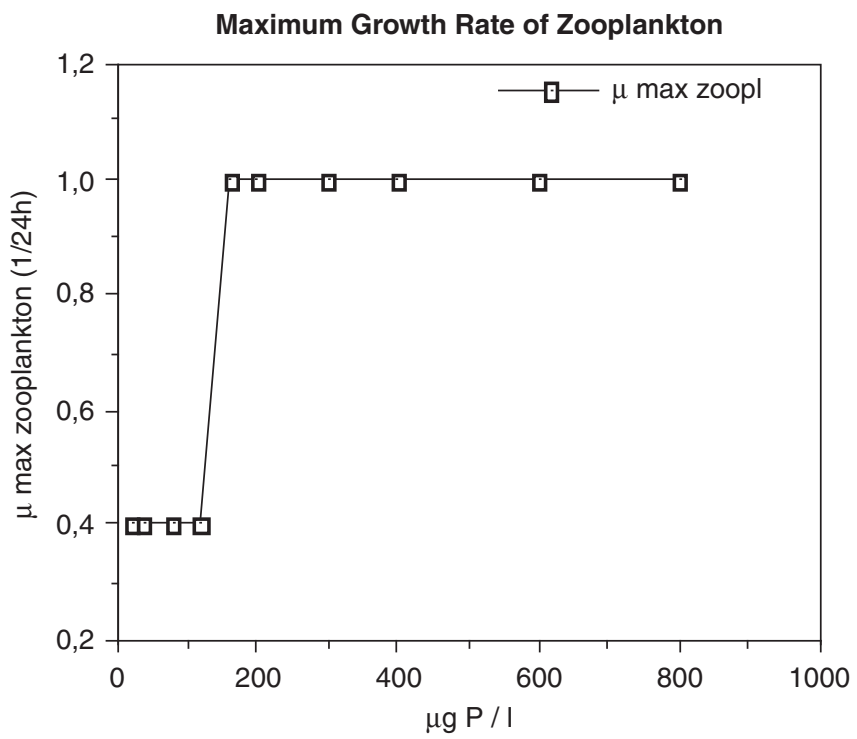

Figure 6: The maximum growth rate of zooplankton obtained by the SDM approach is plotted against the zooplankton concentration.

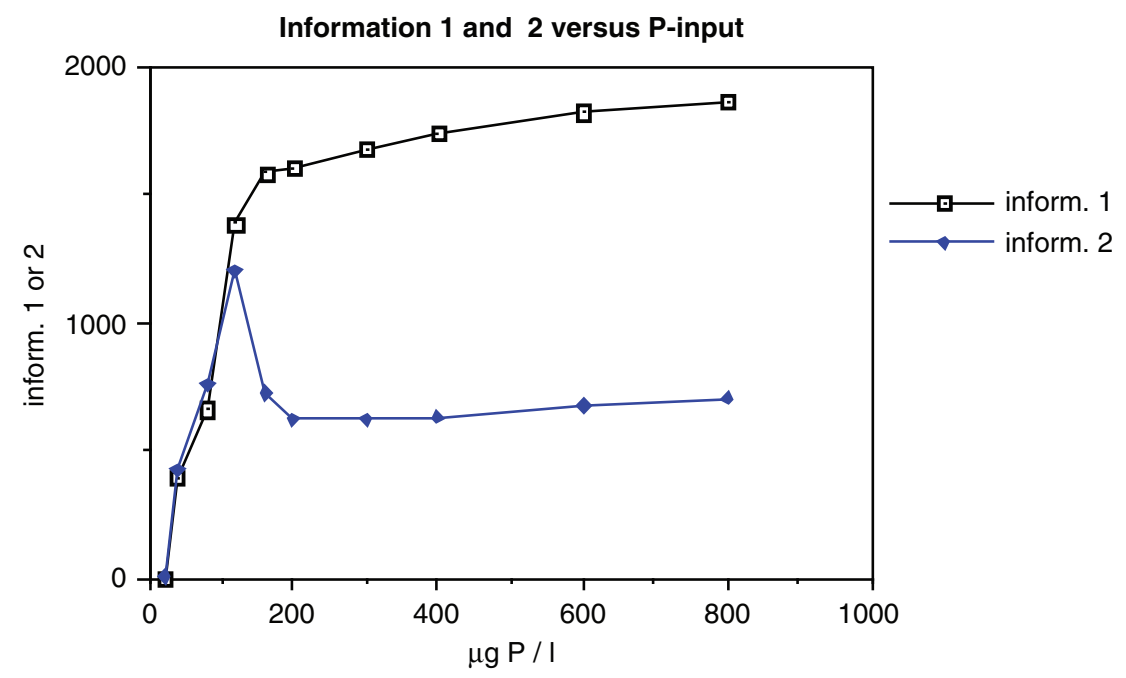

Figure 7: The exergy is plotted against the phosphorus concentration. Information 1 corresponds to a maximum zooplankton growth rate of $1(1 / 24 \mathrm{~h})$ and information 2 corresponds to a maximum zooplankton growth rate of $0.4(1 / 24 \mathrm{~h})$. The other parameters are the same for the two plots, including the maximum phytoplankton growth rate as function of the phosphorus concentration.

Figure 7 shows the eco-exergy, named on the diagram information, with an uptake rate according to the obtained data. The phytoplankton concentration increases for both parameter sets with increasing phosphorus input, as shown Fig. 8, while the planktivorous fish shows a significantly higher level by a grazing rate of $1.01 / 24 \mathrm{~h}$, when the phosphorus concentration is $\geq 0.12 \mathrm{mg} / \mathrm{L}$ (= valid for the high exergy level). Below this concentration, the difference is minor. The concentration of fish 2 is 


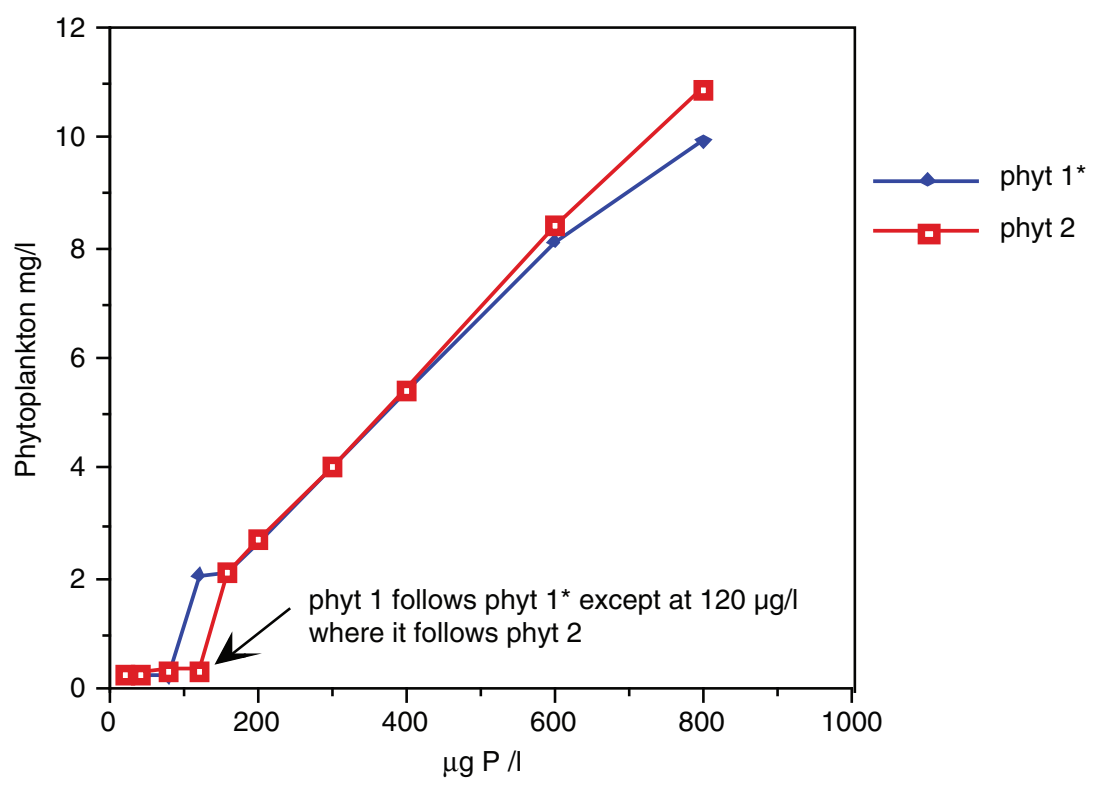

Figure 8: The phytoplankton concentration as function of the phosphorus concentration for parameters corresponding to 'information 1' and 'information 2'; see Fig. 6. The plot named 'phyt 1 *' coincides with 'phyt 1 ', except for a phosphorus concentration of 0.12 $\mathrm{mg} / \mathrm{L}$, where the model shows limit cycles. At this concentration, information $1^{*}$ represents the higher phytoplankton concentration, while information 1 represents the lower phytoplankton concentration. Notice that the structural dynamic approach can explain the hysteresis reactions.

higher for the case 2 corresponding to a grazing rate of $0.41 / 24 \mathrm{~h}$ for phosphorus concentrations below $0.12 \mathrm{mg} / \mathrm{L}$. Above this value, the differences are minor, but at a phosphorus concentration of $0.12 \mathrm{mg} / \mathrm{L}$, the level is significantly higher for a grazing rate of $1.01 / 24 \mathrm{~h}$, particularly for the lower exergy level, where the zooplankton level is also the highest.

If it is presumed that eco-exergy can be used as a goal function in ecological modeling, then the results seem to be able to explain why we observe a shift in grazing rate of zooplankton at a phosphorus concentration in the range of $0.1-0.15 \mathrm{mg} / \mathrm{L}$. The ecosystem selects the smaller species of zooplankton above this level of phosphorus because it means a higher level of the eco-exergy, which can be translated to a higher rate of survival and growth. It is interesting that this shift in grazing rate only gives a little higher level of zooplankton, while the eco-exergy index level gets significantly higher by this shift, which may be translated as survival and growth for the entire ecosystem. Simultaneously, a shift from a zooplankton, predatory fish-dominated system to a system dominated by phytoplankton and particularly by planktivorous fish takes place.

It is interesting that the levels of eco-exergy and the four biological components of the model for phosphorus concentrations at or below $0.12 \mathrm{mg} / \mathrm{L}$ parameter combinations are only slightly different for the two parameter combinations. It can explain why biomanipulation is more successful in this concentration range. Above $0.12 \mathrm{mg} / \mathrm{L}$ the differences are much more pronounced and the exergy index level is clearly higher for a grazing rate of $1.01 / 24 \mathrm{~h}$. It should therefore be expected that the ecosystem after the use of biomanipulation easily falls back to the dominance of planktivorous fish and phytoplankton. These observations are consistent with the general experience of success and failure of biomanipulation; see above. 
An interpretation of the results points toward a shift at $0.12 \mathrm{mg} / \mathrm{L}$, where a grazing rate of $1.01 / 24$ $\mathrm{h}$ yields limit cycles. It indicates an instability and probably an easy shift to a grazing rate of $0.41 / 24$ $\mathrm{h}$, although the exergy level is in average highest for the higher grazing rate. A preference for a grazing rate of $1.01 / 24 \mathrm{~h}$ at this phosphorus concentration should therefore be expected, but a lower or higher level of zooplankton is dependent on the initial conditions.

If the concentrations of zooplankton and fish 2 is low, and high for fish 1 and phytoplankton, that is, the system is coming from higher phosphorus concentrations, then the simulation gives with high probability a low concentration of zooplankton and fish 2 . When the system is coming from high concentrations of zooplankton and of fish 2, the simulation gives with high probability a high concentration of zooplankton and fish 2, which corresponds to an eco-exergy index level slightly lower than that which is obtained by a grazing rate of $0.41 / 24 \mathrm{~h}$. This grazing rate will therefore still persist. As it also takes time to recover, the population of zooplankton and particularly of fish 2 and in the other direction of fish 1, these observations explain the presence of hysteresis reactions.

The model is considered to have general applicability and has been used to discuss the general relationship between nutrient level and vegetative biomass and the general experiences by application of biomanipulation. The model could probably be improved by introducing size preference for the grazing and the two predation processes, which is in accordance with numerous observations. In spite of these shortcomings of the applied model, it has been possible to give a semi-quantitative description of the reaction to changed nutrient level and biomanipulation, and even to indicate an approximately correct phosphorus concentration, where the structural changes may occur. This may be due to an increased robustness by the SDM approach. It is possible to model competition between a few species with quite different properties, but the SDM approach makes it feasible to include more species even with only slightly different properties, which is impossible by the usual modeling approach; see also the unsuccessful attempt to do so by Nielsen $[4,5]$. The rigid parameters of the various species make it difficult for the species to survive under changing circumstances. After some time, only a few species will still be present in the model, opposite what is the case in reality, where more species survive because they are able to adapt to the changing circumstances. It is important to capture this feature in our models. The SDMs seem promising to apply in lake management, as this type of models is applicable to explain our experience in the use of biomanipulation. It has the advantage compared with the use of catastrophe models, which can also be used to explain success and failure of biomanipulation that it is able also to describe the observed shifts in species composition.

\section{DEVELOPMENT OF SDM TO DESCRIBE THE COMPETITION BETWEEN PHYTOPLANKTON AND SUBMERGED VEGETATION}

This illustration of the use of SDM has been presented in more details in Jørgensen [3]. Zhang et al. $[33,34]$ have developed a SDMs by use of STELLA. The conceptual diagram of the model is shown in Fig. 9. The model was developed by use of the data from Lake Mogan close to Ankara, Turkey. Phosphorus is the liming factor for eutrophication in the lake; this is interesting because it is a shallow lake with a competition between phytoplankton and submerged vegetation. The model has seven state variables: soluble P, denoted as PS, phosphorus in phytoplankton, PA, phosphorus in zooplankton, PZ, phosphorus in detritus, PD, phosphorus in submerged plants, denoted as PSM, exchangeable phosphorus in the sediment, PEX, and phosphorus in pore water, PP. The processes are inflows and outflows of phosphorus, phosphorus in phytoplankton, and phosphorus in detritus. Soluble phosphorus is taken up by phytoplankton - the process is named uptakeP. Zooplankton grazes on phytoplankton indicated as 'grz' on the diagram. The settling of detritus and phytoplankton is covered by a first-order reaction. A part of the settled material is lost as non-exchangeable 


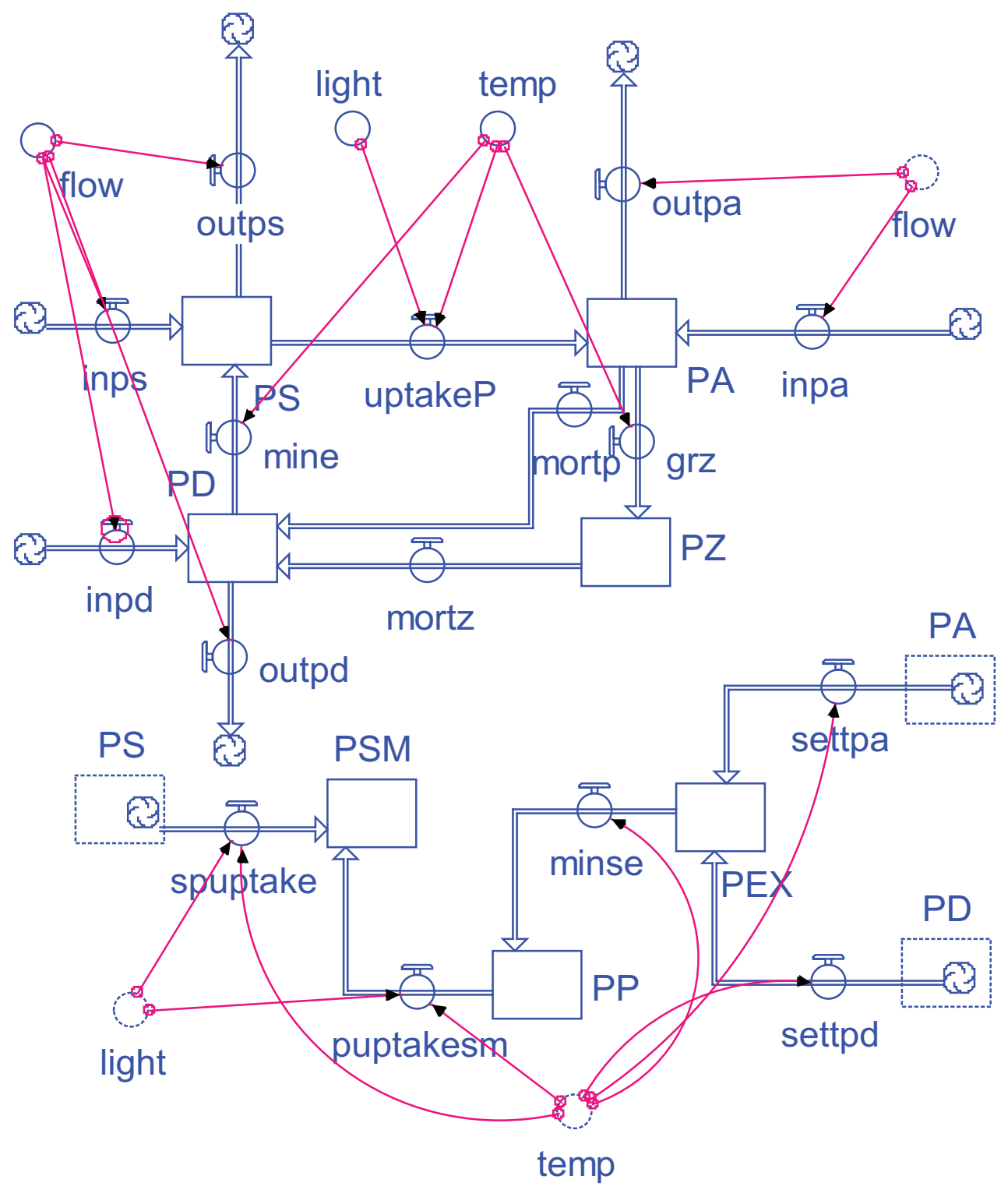

Figure 9: The conceptual diagram of the Lake Mogan eutrophication model focusing on the cycling of phosphorus. The model has seven state variables: soluble P, denoted as PS, phosphorus in phytoplankton, PA, phosphorus in zooplankton, PZ, phosphorus in detritus, PD, phosphorus in submerged plants, denoted as PSM, exchangeable phosphorus in the sediment, PEX, and phosphorus in pore water, PP.

phosphorus, while the exchangeable fraction proceeds to the state variable exchangeable phosphorus, PEX. A mineralization of the exchangeable phosphorus takes place in the sediment - the process is named 'minse' in the diagram. 
Mineralization in the water phase of detritus phosphorus is a process named mine. Temperature influences all the process rates. Light is, of course, considered a climatic forcing function influencing the growth of both phytoplankton and submerged plants. The submerged plants take most phosphorus up from the sediment, but the model considers both uptake of phosphorus from water and sediment by the submerged plants.

The SDM approach was used in the presented eutrophication model to examine:

1. The possibilities to improve calibration. Usually eutrophication models are used for one set of parameters for the entire annual cycle, but almost all lakes have different species of phytoplankton and zooplankton in different seasons, that is, in the spring, in the summer, and in the fall, because the conditions are different from season to season. The question is if we could include these changes of the parameters corresponding to the shifts in species composition from season to season, would we then obtain a better calibration and validation? In other words, could we improve calibration and validation, if we would use the SDM approach not only for development of prognoses but also for the calibration and validation?

2. Whether the catastrophic changes from submerged vegetation dominance to phytoplankton dominance, that is, described by Scheffer et al. [35] could be covered by the SDM?

The use of the SDM approach in the calibration phase was carried out by use of the following stepwise method:

(I) To reduce the number of parameter combination, the allometric relationships between parameters of phytoplankton and zooplankton and their sizes were applied: In accordance to the procedure for development of SDMs, see Fig. 2, the model should be tested for all combinations of at least three possible values of the variable parameters. It means that if seven parameters are made structurally dynamic as it was decided for the eutrophication model in this case, it is required to run the model $3^{7}$ times $=2187$, but if as it is done by use of the allometric principles is possible to reduce the parameters to two - namely size of phytoplankton and size of zooplankton - it is only required to run the model $3 \times 3$ times or 9 times.

(II) First, the model was calibrated using the usual trial and error method to find the combinations of parameters that would give the smallest discrepancy between model results and observations. These parameters were maintained for the subsequent application of the SDM approach, except for the seven parameters listed above - they would be determined by a current change of the size according to the SDM approach, described as point III.

(III) Nine runs (three phytoplankton sizes - the same, $10 \%$ increase and $10 \%$ decrease and three zooplankton sizes - the same, $10 \%$ increase and 10\% decrease) are performed from day 0 to day $\mathrm{X}$ ( $\mathrm{X}=10$ days was chosen for the Lake Mogan model). The combination of size for phytoplankton and zooplankton that gave the highest eco-exergy value was selected for the 10 days. Eco-exergy was calculated for the model as Eco-exergy $=21 *$ phytoplankton $+135^{*}$ zooplankton $+100^{*}$ submerged vegetation + detritus. This procedure was repeated every 10 days. After an annual model run, it was possible to give a graph or table of the phytoplankton and zooplankton sizes that would currently - it means every 10 days - optimize the eco-exergy of the model. The sizes were 'translated' to the seven parameters that were selected as structurally dynamic - see the list above.

(IV) The size of phytoplankton and zooplankton that was found as function of time was introduced to the model and the other model parameters, that is, all the parameter minus the seven phytoplankton and zooplankton parameters were now calibrated again to account in this calibration for the influence of our knowledge about the phytoplankton and zooplankton size as function of time. Principles III and IV should be repeated until there are no further changes of the parameters obtained. 


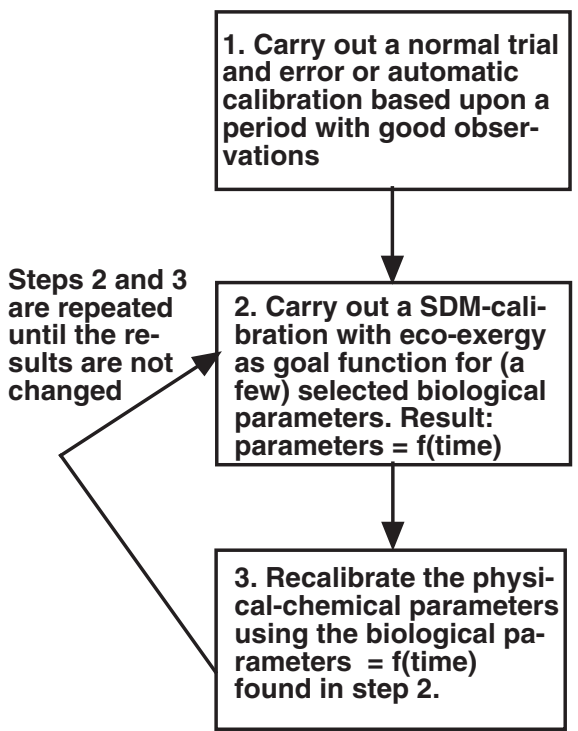

Figure 10: The diagram shows how the SDM approach is applied for an improved calibration procedure. The steps 2 and 3 are applied iterative until the results of ten calibrations are not changed further.

This stepwise procedure - see the steps 1-3 in Fig. 10 - is, of course, more cumbersome than to use an automatic SDM programmed in $\mathrm{C}++$, but still it takes only a few days to obtain this SDM calibration, while the conventional calibration by trial and error may even require much longer time. The procedures I-IV are represented schematically in Fig. 10. For the Lake Mogan model, it was found that the standard deviation expressing the difference between the modeled value and observed value of phytoplankton phosphorus for the SDM calibration was $10.9 \%$ versus $18 \%$ for the usual calibration procedure. For phytoplankton, zooplankton, and soluble phosphorus, which were considered the most important state variables, the standard deviation of $8.2 \%$ was observed for the SDM calibration and $10.7 \%$ for the usual calibration. The graphs for the observations and the model outputs of the two different calibration procedures are shown in Fig. 11.

The SDM was used after calibration to answer the following question: Is it possible to describe the catastrophic changes from submerged vegetation dominance to phytoplankton dominance and back again, that is, described by Scheffer et al. [35], by application of the SDM of Lake Mogan? According to Scheffer et al., we should expect that submerged vegetation is replaced by phytoplankton if we increase the phosphorus concentration to $250 \mu \mu \mathrm{g} / \mathrm{L}$ and that the submerged vegetation does not return when we decrease the phosphorus concentration before at about $100 \mu \mathrm{g} / \mathrm{L}$. Can we in other words simulate the described hysteresis behavior by use of the developed SDM for Lake Mogan? The phosphorus concentration in the lake is about $80-85 \mu \mathrm{g} / \mathrm{L}$, according to the observations, and it was the concentration applied for the calibration described above.

To answer the question, the phosphorus concentration in the water was increased a factor five times which implies that we should expect a phosphorus concentration after a couple of years corresponding to the retention time of about $400 \mu \mathrm{g} / \mathrm{L}$. Afterward, the phosphorus concentration was reduced to the present level of $80-85 \mu \mathrm{g} / \mathrm{L}$. Figure 12 illustrates the results of these changes in the phosphorus concentration from $80-85$ to $400 \mu \mathrm{g} / \mathrm{L}$ and from 400 to $80-85 \mu \mathrm{g} / \mathrm{L}$. 


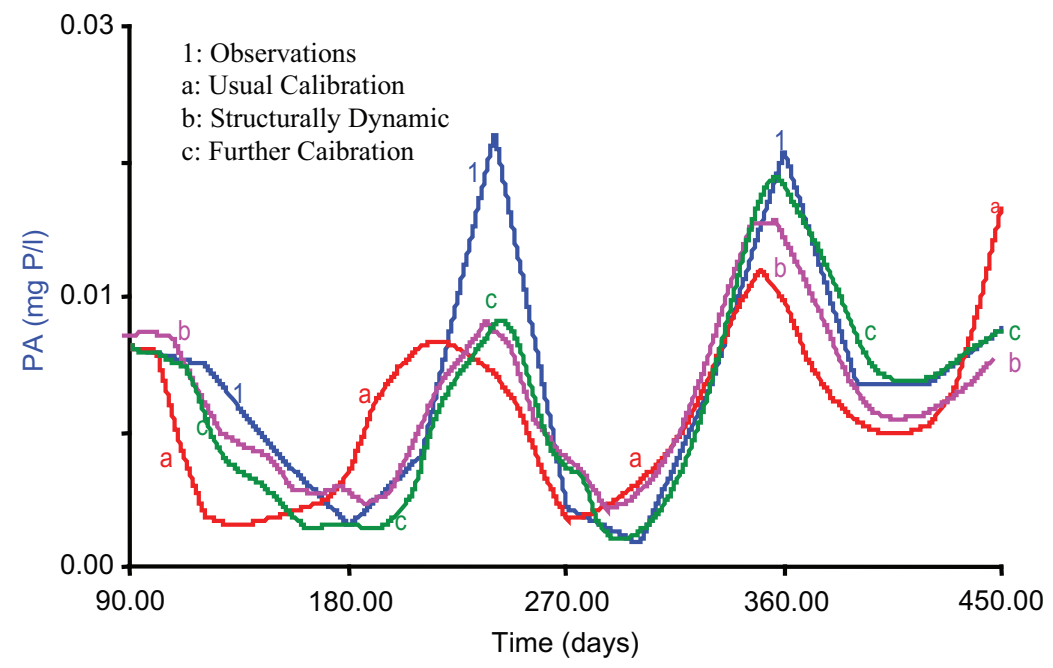

Figure 11: The phytoplankton $-\mathrm{P}$ as $\mathrm{mg} / \mathrm{L}$ is shown for (1) observations (a) the calibration obtained by the conventional trial and error calibration, (b) the calibration of the SDM (the method see the text), (c) the calibration obtained after the non- structural dynamic parameters have been calibrated by use of the structural dynamic parameters obtained by procedure (b). The time is from October 1 (day 90) to October 1 (day 450). The results of the final calibration, SDM calibration followed by the normal calibration of the non-structural dynamic parameters (c) are very well in accordance with the observation, except for the first peak during late April. The deviation between the modeled and the observed phytoplankton concentration at the second peak in July is only $8 \%$ relatively, while the trial and error here gives a deviation of almost $40 \%$.

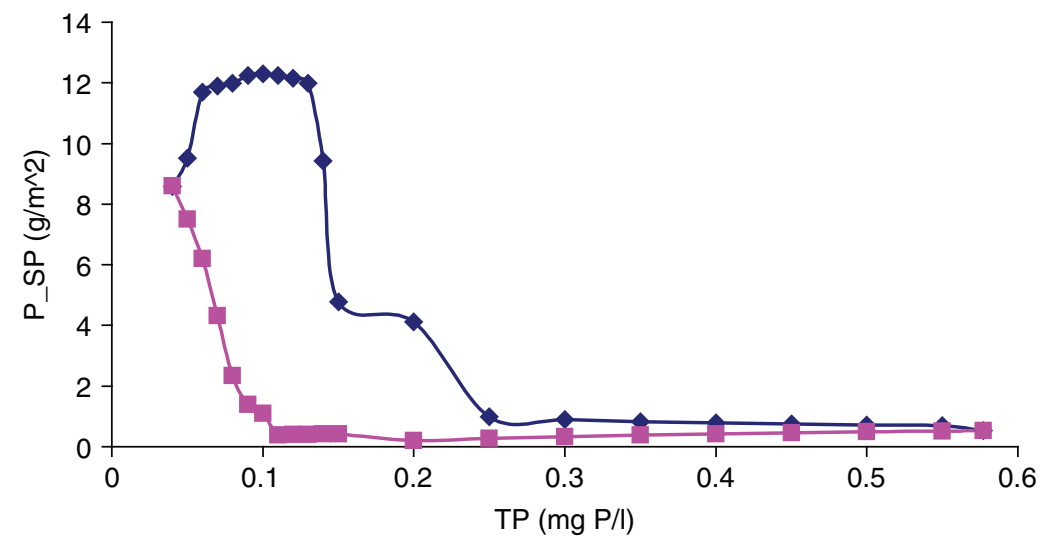

Figure 12: The graphs show the reaction of submerged plants to an increase in phosphorus of 400 $\mu \mathrm{g} / \mathrm{L}$ followed by return to the original concentration of about $80-85 \mu \mathrm{g} / \mathrm{L}$. When the phosphorus concentration increases, the P-SP also increases, but at about $250 \mu \mathrm{g} / \mathrm{L}$, the submerged vegetation disappears and is replaced by phytoplankton-P. When the concentration returns to the $80-85 \mu \mathrm{g} / \mathrm{L}$, the submerged vegetation emerges when the concentration is at $100 \mu \mathrm{g} / \mathrm{L}$. The hysteresis behavior is completely in accordance with Scheffer et al.; see [35]. 


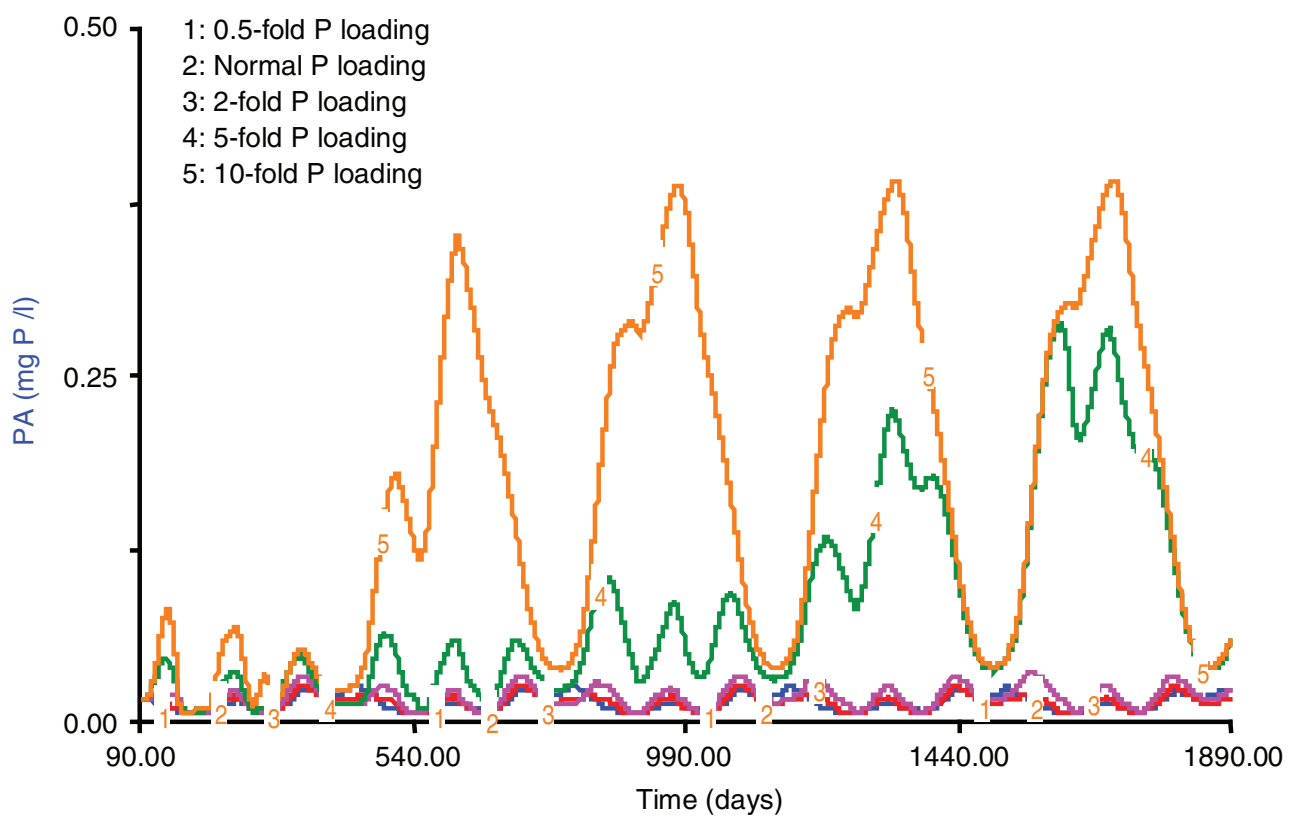

Figure 13: The phytoplankton-P concentration as function of time is shown when the phosphorus concentration of the water flowing into the lake are increased by (1) a factor of 0.5, (2) normal (factor of 1.0), (3) a factor of 2, (4) a factor of 5, and (5) a factor of 10. The present concentration of phosphorus in the lake is $80-85 \mu \mathrm{g} / \mathrm{L}$. (1), (2), and (3) give no changes, while (4) and (5) give a significant increase of phytoplankton, which becomes dominant.

Figure 13 show the phytoplankton-P concentrations as function of time for five different phosphorus concentrations of the water flowing into the lake: (1) 0.5 times the present level, (2) the present level, (3) two times the present level, (4) five times the present level, and (5) ten times the present level. As indicated above, the present level is $80-85 \mu \mathrm{g} / \mathrm{L}$. Figure 14 shows the submerged plant as $\mathrm{g} / \mathrm{m}^{2}$ as function of time for the same five phosphorus concentration of the water flowing to the lake. The shift in dominance from submerged vegetation to phytoplankton is very clear for the phosphorus concentrations five and ten times the present value.

It is possible to conclude from the presented application of SDM that the use of SDM approach for the calibration enables improvement in the calibration results and that it is possible to answer the raised questions about the catastrophic changes by use of SDM.

\subsection{SDM developed for Lake Fure}

Lake Fure is the deepest lakes in Denmark. It has a surface area of 941 ha and an average depth of $13.5 \mathrm{~m}$. It consists of two ecologically different parts that are connected: the main basin, which is the large and deep part with an average depth of $16.5 \mathrm{~m}$ and the maximum depth of $37.7 \mathrm{~m}$, and the shallow small part, which is called Store Kalv and has a mean and a maximum depth of $2.5 \mathrm{~m}$ and $4.5 \mathrm{~m}$, respectively. The lake is situated $12-17 \mathrm{~km}$ from the center of Copenhagen and has, therefore, great recreational value.

The eutrophication of the lake increased significantly in the 1950s and 1960s, due to a growing population in the suburbs north of Copenhagen. The waste water was treated mechanically and 


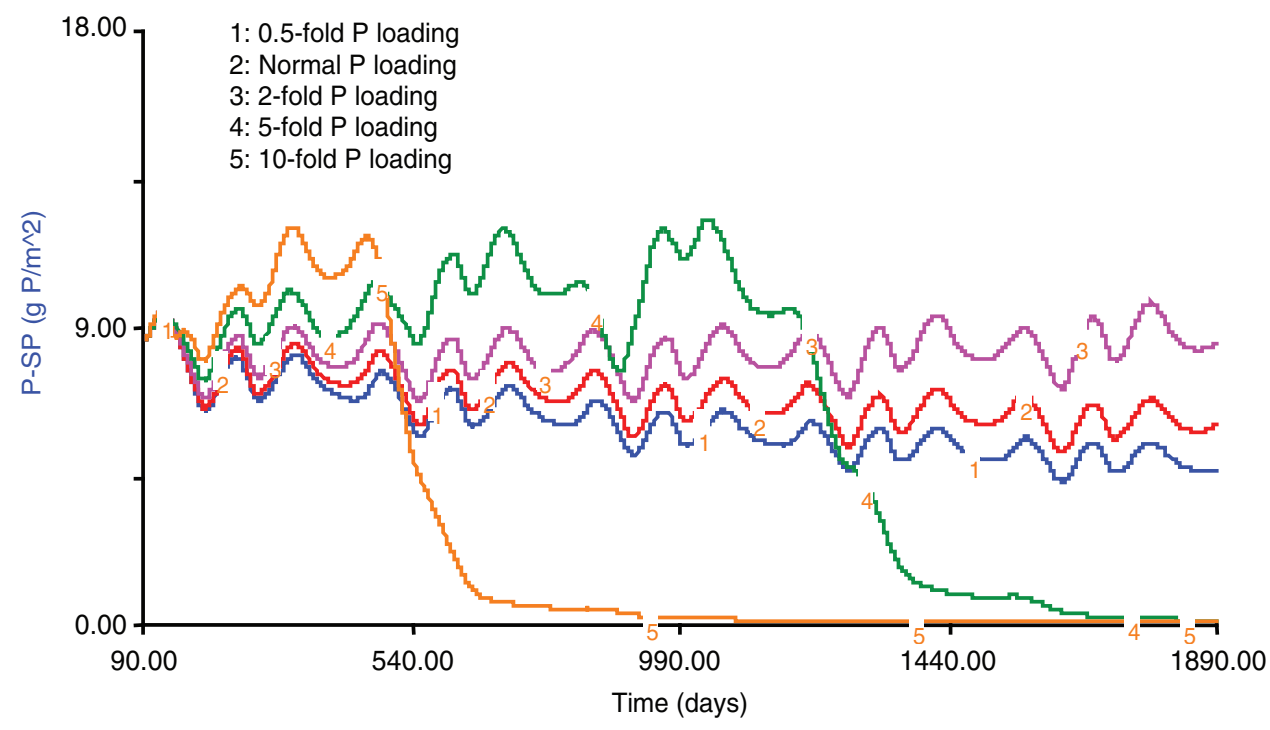

Figure 14: The submerged plant-concentration as $\mathrm{gP} / \mathrm{m}^{2}$ as function of time is shown when the phosphorus concentration of the water flowing into the lake are increased by (1) a factor of 0.5, (2) normal (factor of 1.0), (3) a factor of 2, (4) a factor of 5, and (5) a factor of 10 . The present concentration of phosphorus in the lake is $80-85 \mu \mathrm{g} / \mathrm{L}$. (1), (2), and (3) give no changes, while (4) and (5) first give a minor increase of the concentration followed by a significant decrease, when phytoplankton becomes dominant; compare with Figure 13.

biologically, but there was no removal of nutrients. It was, therefore, decided in the late 1960 s to take measures to reduce the eutrophication. In 1970, it was decided that the three municipalities discharging waste water to the lake could either choose to treat the waste water effectively by removal of nutrients or pump the waste water to the sea. A maximum phosphorus concentration of $0.2 \mathrm{mg} / \mathrm{L}$ and a maximum nitrogen concentration of $8 \mathrm{mg} / \mathrm{L}$ was required for the treatment of waste water, if the municipality would select the treatment solution. One of the three municipality selected the treatment solution, while the other two municipality preferred to pump the mechanically, biologically treated water to the sea. A model developed at that time showed that the treatment solution was the best solution for the lake due to a faster recovery of the lake. The lake had a water retention of approximately 16 years and the pumping of round 2 million $\mathrm{m}^{3}$ to the sea prolonged the retention to about 21 years, which implied, of course, a slower reduction of the eutrophication.

The nutrient balances of the lake, in 1972, just before the implementation of the above mentioned solution are shown in Fig. 15. The measures taken reduced the phosphorus and nitrogen discharge to the lake by waste water to less than $1 \mathrm{t}$ and about $3 \mathrm{t}$, respectively. The three other sources of nutrients, drainage water, storm water overflow, and precipitation were unchanged. During the period from 1972 to 2000 the municipalities were able to reduce the other sources slightly as it can be seen in Fig. 16 showing the nutrient balances for year 2000. The nutrient input from storm water was reduced by enlarging the storm water capacity. It is to be noted, however, that the internal loading was not reduced which is at least partly due to long retention time. It indicates that the two 


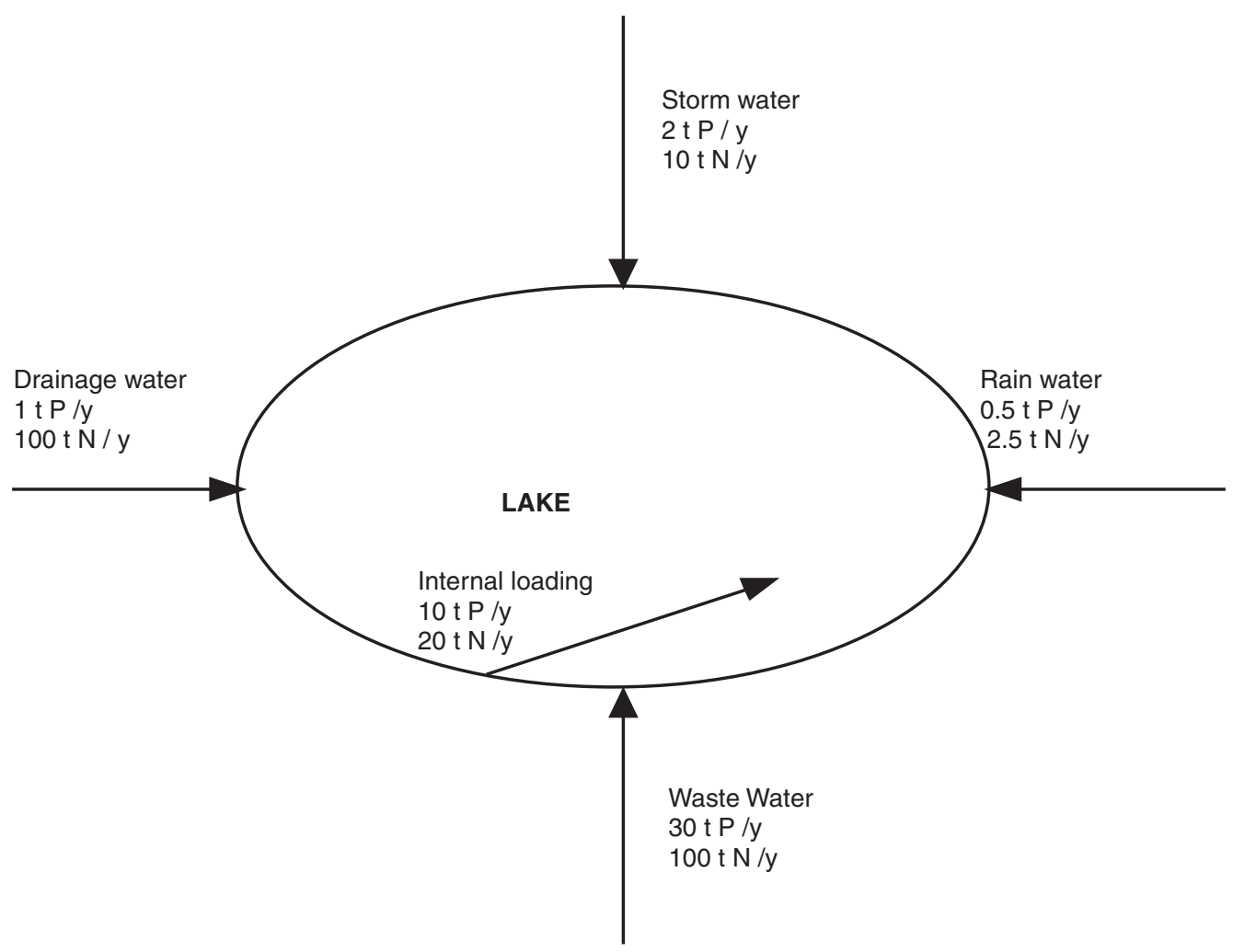

Figure 15: The nutrient balances in year 1972 before the loading of nutrients from waste water was reduced.

municipalities that preferred to pump the waste water to the sea in the early 1970s, and did not accept the model result that the treatment solution would give a faster recovery, were forced in 1986 to include nitrogen and phosphorus removal in the waste water treatment due to introduction of maximum standard for discharge of all waste water, even to waste water discharged directly to the sea.

Shortly after year 2000, it was decided to use restoration methods to recover the lake faster. Two restoration methods were proposed:

1. Aeration of the hypolimnion by oxygen from late April to late October when the lake had a thermocline. The release of phosphorus from the sediment would, thereby, be reduced significantly.

2. Biomanipulation by massive removal of planktivorous fish.

The restoration of the lake started in 2003. A SDM was developed in year 2005; see the paper by Gurkan et al. [36] A SDM was naturally to apply in this case, as structural changes were expected due to reduced internal loading, the removal of a significant part of the planktivorous fish, and further increase of the storm water capacity. The model was used for prognosis about the water quality in year 2010. Figure 17 shows the application of the model results on the nutrient balance and Table 2 shows the changes in the important state variables from 2004 to 2010, according to the prognosis made by the SDM of PAMOLARE. 


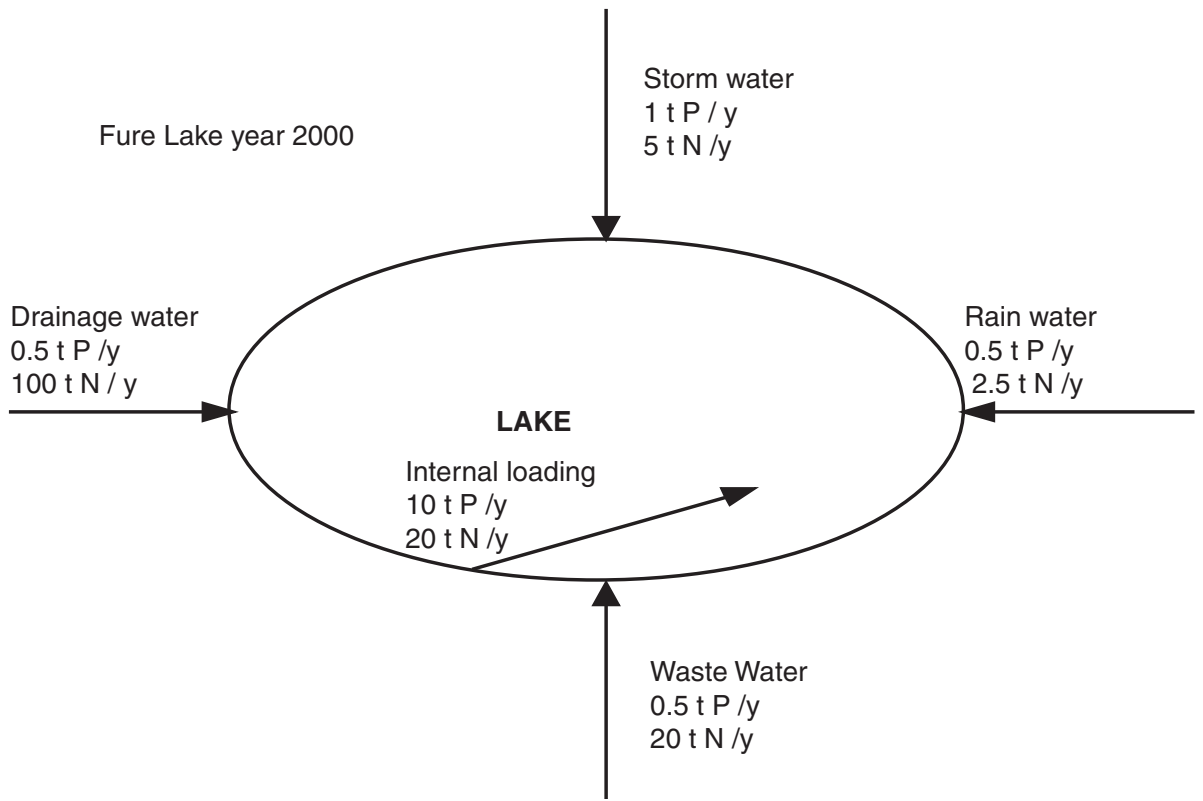

Figure 16: The nutrient balances in year 2000 .

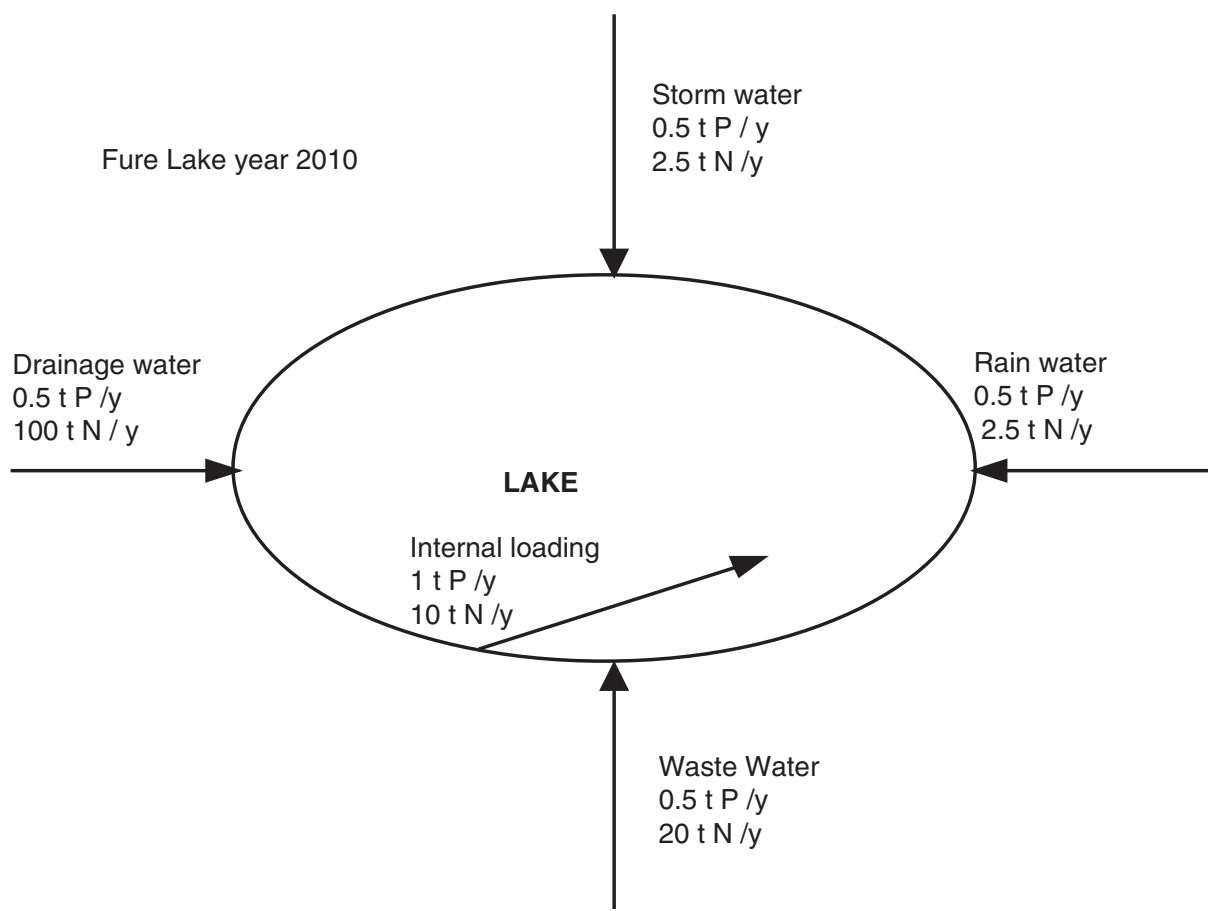

Figure 17: The nutrient balances according the result of the SDM. The internal loading is reduced mainly due to the aeration of the hypolimnion: The phosphorus and nitrogen loading from storm water is reduced due to increase of the storm water capacity. 
Table 2: Changes in important state variables from 2000 to 2010, according to the results of the SDM applied due to restoration project (aeration of hypolimnion, biomanipulation, and increased storm water capacity).

\begin{tabular}{lcc}
\hline State variable & Year 2000 & Year 2010 \\
\hline Total P mg/L & $0.18-0.25$ & $0.02-0.07$ \\
Chl.a maximum (early Aug.) mg/L & 0.044 & 0.022 \\
Transparency minimum (early Aug.) m & 2.2 & 3.6 \\
Zooplankton mg d.w./L & 0.8 & 1.8 \\
\hline
\end{tabular}

\section{SUMMARY AND CONCLUSIONS}

Because ecosystems are adaptive and can change the species compositions, there is a need for models that can consider this characteristic dynamics. SDMs can account for these ecological, dynamic properties. By the use of eco-exergy as goal function, it is possible to develop models that can describe adaptation and shifts in species composition. Twelve structurally dynamic lake models have been developed and three illustrative case studies, among the 12 case studies, are presented in this paper. The three presented case studies show that SDMs can describe the observed structural changes and thereby able to improve the prognoses developed by the models. In addition, it is also possible to improve the calibration of ecological lake models by the use of SDMs because there are clearly seasonal changes of the dominant species in lakes, which makes it difficult to calibrate the models with one parameter to cover the entire year. In contrast, the application of SDMs makes it possible to capture the seasonal changes of the properties of phytoplankton and zooplankton, for example, and thereby improve significantly the calibration.

All the twelve case studies of SDMs of lakes show the same picture [3, 1], and Jørgnesen and Fath, 2011): in most cases it is possible to improve the calibration, the accuracy of the prognoses increases, and it is possible with an acceptable standard deviation to capture the dynamic changes.

SDMs can therefore be recommended to apply, whenever adaptation and structural changes are presumed to take place. It makes it particularly attractive to apply SDMs when models are used for prognoses in environmental management, because prognoses are often considering radical changes of the forcing functions and, therefore, structural changes could most probably take place.

\section{REFERENCES}

[1] Zhang, J., Z. Gurkan and S.E. Jørgensen. Application of eco-energy for assessment of ecosystem health and development of structurally dynamic models. P. Ecological Modelling, 221, pp. 693-702, 2010. doi: http://dx.doi.org/10.1016/j.ecolmodel.2009.10.017

[2] Jørgensen, S.E., An Overview of the model types available for development of ecological models. Ecological Modelling, 215, pp. 3-9, 2008. doi: http://dx.doi.org/10.1016/j.ecolmodel.2008.02.041

[3] Jørgensen, S.E., Ecological Modelling - An Introduction. WIT, Southampton, p. 190, 2009.

[4] Nielsen, S.N., Application of maximum exergy in structural dynamic models, Ph.D. Thesis. National Environmental Research Institute, Denmark, p. 51, 1992a.

[5] Nielsen, S.N., Strategies for structural-dynamical modelling. Ecol. Modelling, Ecological Modelling, 63, pp. 91-101, 1992b. doi: http://dx.doi.org/10.1016/0304-3800(92)90063-K 
[6] Straskraba, M., Natural control mechanisms in models of aquatic ecosystems. Ecol. Modelling, 6, pp. 305-322, 1979. doi: http://dx.doi.org/10.1016/0304-3800(79)90043-7

[7] Straskraba, M., 1980 . Cybernetic-categories of ecosystem dynamics. ISEM-Journal, 2, pp. 81-96.

[8] Jørgensen, S.E., \& Mejer, H.F., A holistic approach to ecological modelling. Ecol. Modelling, 7, pp. 169-189, 1979. doi: http://dx.doi.org/10.1016/0304-3800(79)90068-1

[9] Jørgensen, S.E., A holistic approach to ecological modelling by application of thermoDynamics. Systems and Energy. eds W. Mitsch et. al., Ann Arbor, 1982.

[10] Jørgensen, S.E., Structural dynamic model. Ecol. Modelling, 31, pp. 1-9, 1986. doi: http:// dx.doi.org/10.1016/0304-3800(86)90051-7

[11] Jørgensen, S.E., Use of models as experimental tools to show that structural changes are accompanied by increased exergy. Ecol. Modelling, 41, pp. 117-126, 1988. doi: http://dx.doi. org/10.1016/0304-3800(88)90049-X

[12] Jørgensen, S.E., Ecosystem theory, ecological buffer capacity, uncertainty and complexity. Ecol. Modelling, 52, pp. 125-133, 1990. doi: http://dx.doi.org/10.1016/0304-3800(90)90013-7

[13] Jørgensen, S.E., Parameters, Ecological constraints and exergy. Ecol. Modelling, 62, pp. 163-170, 1992a. doi: http://dx.doi.org/10.1016/0304-3800(92)90088-V

[14] Jørgensen, S.E., Development of models able to account for changes in species composition. Ecol. Modelling, 62, 195-208, 1992b. doi: http://dx.doi.org/10.1016/0304-3800(92)90091-R

[15] Jørgensen, S.E., \& Mejer, J.F., Ecological buffer capacity. Ecol. Modelling, 3, pp. 39-61, 1977.

[16] Jørgensen, S.E., \& Svirezhev Y. Toward a Thermodynamic Theory for Ecological Systems. Amsterdam, Oxford: Elsevier. p. 366, 2005. doi: http://dx.doi.org/10.1016/0304-3800(77)90023-0

[17] Schrødinger, E., What is Life? Cambridge University Press. p. 186, 1944.

[18] Jørgensen, S.E., Ladegaard, N., Debeljak, M., Marques, J.C., Calculations of exergy for organisms. Ecol. Model, 185, pp. 165-175, 2005. doi: http://dx.doi.org/10.1016/j.ecolmodel.2004.11.020

[19] Hosper, S.H. Biomanipulation, new perspective for restoring shallow, eutrophic lakes in The Netherlands. Hydrobiol. Bull, 73, pp. 11-18, 1989.

[20] Van Donk, E., Gulati, R.D., \& Grimm, M.P. Food web manipulation in lake Zwemlust: positive and negative effects during the first two years. Hydrobiol. Bull, 23, pp. 19-35, 1989. doi: http:// dx.doi.org/10.1007/BF02286424

[21] de Bernardi, R. Biomanipulation of aquatic food chains to improve water quality in eutrophic lakes 195-215. In Ecological Assessment of Environmental Degradation, Pollution and Recovery, ed O. Ravera. Amsterdam: Elsevier Sci. Publ, p. 356, 1989.

[22] Sas, H. (Coordination) Lake restoration by reduction of nutrient loading. Expectations, experiences, extrapolations. St. Augustin. Academia Verl. Richarz, p. 497, 1989.

[23] de Bernardi, R., \& Giussani, G, Biomanipulation: Bases for a Top-down Control 1-14. In Guidelines of Lake Management, Volume 7. Biomanipulation in Lakes and Reservoirs, edited by De Bernardi, R., \& Giussani, G. ILEC and UNEP, p. 211, 1995.

[24] Willemsen, J. Fishery aspects of eutrophication. Hydrobiol. Bull, 14, pp. 12-21, 1980. doi: http://dx.doi.org/10.1007/BF02260268

[25] Lammens, E.H.R.R. Trophic interactions in the hypertrophic Lake Tjeukemeer: Top-down and bottom-up effects in relation to hydrology, predation and bioturbation, during the period 1974-1988. Limnologica (Berlin), 19, pp. 81-85, 1988.

[26] Jeppesen, E.J. et al. Fish manipulation as a lake restoration tool in shallow, eutrophic temperate lakes. Cross-analysis of three Danish Case Studies. Hydrobiologia, 200/201, pp. 205-218, 1990. doi: http://dx.doi.org/10.1007/BF02530340 
[27] Benndorf, J., Conditions for effective biomanipulation. Conclusions derived from wholelake experiments in Europe. Hydrobiologia, 200/201, pp. 187-203, 1990. doi: http://dx.doi. org/10.1007/BF02530339

[28] Shapiro, J. Biomanipulation. the next phase-making it stable. Hydrobiologia, 200/210, pp. 13-27, 1990. doi: http://dx.doi.org/10.1007/BF02530325

[29] Koschel, R., Kasprzak, Krienitz, L. and Ronneberger, D. Long term effects of reduced nutrient loading and food-web manipulation on plankton in a stratified Baltic hard water lake. Verh. int. ver. Limnol, 25, pp. 647-651, 1993.

[30] Scheffer, M. Simple models as useful tools for ecologists. Elsevier. Amsterdam. pp. 192, 1990.

[31] Giussani, G., \& Galanti, G. Case Study: Lake Candia (Northern Italy) 135-146. In Guidelines of Lake Management, Volume 7. Biomanipulation in Lakes and Reservoirs, edited by De Bernardi, R. and Giussani, G. Biomanipulation. ILEC and UNEP, pp. 211,1995.

[32] Jørgensen, S.E., \& de Bernardi, R., The use of structural dynamic models to explain the success and failure of biomanipulation. Hydrobiologia, 379, pp. 147-158, 1998. doi: http://dx.doi. org/10.1023/A:1003453100523

[33] Zhang, J., Jørgensen, S.E., Tan C.O., Beklioglu, M., A structurally dynamic modelling - Lake Mogan, Turkey as a case study. Ecological Modelling, 164, pp. 103-120, 2003a. doi: http:// dx.doi.org/10.1016/S0304-3800(03)00051-6

[34] Zhang, J., Jørgensen, S.E., Tan C.O., Beklioglu, M., Hysteresis in vegetation shift - lake Mogan Prognoses. Ecological Modelling, 164, pp. 227-238, 2003b. doi: http://dx.doi.org/10.1016/ S0304-3800(03)00050-4

[35] Scheffer, M., Carpenter, S., Foley, J.A., Folke, C., \& Walker, B. Castrophic changes Ecosystems. Nature, 413, pp. 591-596, 2001. doi: http://dx.doi.org/10.1038/35098000

[36] Gurkan, Z., Zhang, J., \& Jørgensen, S.E. Development of a structurally dynamic model for Forecasting the effects of restoration of lakes. Ecological Modelling, 197, pp. 89-103, 2006. doi: http://dx.doi.org/10.1016/j.ecolmodel.2006.03.006

[37] Jørgensen, S.E. \& Fath, B. Fundamentals of ecological modelling, 4th edition, p. 360, 2011.

[38] Peters, R.H. The ecological implications of body size. Cambridge: Cambridge University Press, p. 329, 1983. doi: http://dx.doi.org/10.1017/CBO9780511608551 